\title{
A Plan for Water Quality Improvement in the Tamar Estuary and Esk rivers
}

\author{
$\underline{\text { R.A. Kelly }}^{\text {a }}$, A. Locatellib ${ }^{\mathrm{b}}$ and M. White \\ a isNRM Pty Ltd, PO Box 8017 Trevallyn, TAS 7250 and b NRM North
}

Email: rebecca@isnrm.com.au

\begin{abstract}
The Tamar Estuary and Esk Rivers (TEER) catchments cover nearly 15\% of Tasmania's landmass. The North and South Esk Rivers drain into the Tamar Estuary which extends approximately $70 \mathrm{~km}$ from Launceston to Bass Strait. The region sustains a diverse range of land uses, including grazing, dairy, cropping, plantation and native forestry, mining, heavy industry, urban, rural residential and nature conservation areas. It provides substantial input to Tasmania's economy as well as sustaining key ecological assets and communities. There are 26 wastewater treatment plants discharging into the rivers and estuary, many of which are near the end of their lifecyle and in need of upgrade.

The Tamar Estuary is a mesotidal drowned river valley, the only estuary of this type in Tasmania. It is tidal for its whole length to the First Basin on the South Esk and on the North Esk to St Leonards, with a 3.5 metre tide occurring twice a day in Launceston. The upper estuary has a long history of dredging and community concern over sediment build-up. Other water quality issues relate to elevated nutrient and pathogen levels in areas of the estuary and its tributaries as well as heavy metal contamination in some areas of the estuary and parts of the freshwater system.
\end{abstract}

To provide a coordinated management approach and guide for investment in activities to protect, maintain and restore the health of the catchment, NRM North established the Tamar Estuary and Esk Rivers Program (TEER) in 2008. A key goal of the TEER Program is to improve scientific understanding of the issues impacting upon the health of waterways so that priority areas requiring investment in on-ground works can be better identified and targeted. The TEER Program is a regional partnership between the agencies with a statutory responsibility for waterway management and includes local and state governments, Hydro Tasmania and TasWater. The TEER Program also fosters collaborative partnerships and works closely with a range of industry, business, research, government and community groups to coordinate activities to reduce pollutants entering waterways and to monitor and report on waterway health.

The TEER Program has developed a Water Quality Improvement Plan to provide a long-term blueprint for maintaining and improving water quality in the estuary and its tributaries. The TEER program is strongly collaborative and the Plan has been developed using the strong linkages already developed as well as through additional collaborative and consultative efforts with the broader community. A computer-based decision support system, the CAPER DSS, has been constructed to support development of the Plan. This DSS builds on detailed modelling already undertaken in the catchment and estuary as well as a substantial body of knowledge that has been developed through other studies in the catchment and elsewhere. The DSS allows alternative scenarios to be considered and costed for the Plan, to inform selection of appropriate management strategies. The aim is to develop a Plan with strong community support through a collaborative, consensus building approach. The Plan contains recommendations across the full range of activities undertaken in the catchment, with no simple fix-all solutions.

This paper describes the WQIP development process before providing an example of the type of scenario analysis undertaken with the CAPER DSS that has been included in the Plan. This scenario illustrates one recurring theme of the Plan - that change can be both a threat and an opportunity in terms of water quality. With high levels of adoption of best management practice, land use changes can in some cases be accommodated with little impact on water quality, or even with small benefits to water quality where land uses that are poorly managed or otherwise associated with high pollutant loads are replaced.

Keywords: $\quad$ Water quality improvement plan, decision support system (DSS), CAPER DSS 


\section{INTRODUCTION}

The Tamar River estuary is located in North Eastern Tasmania. The Tamar Estuary and Esk Rivers (TEER) catchments cover nearly $15 \%$ of Tasmania's landmass. The Tamar Estuary extends approximately $70 \mathrm{~km}$ from Launceston to Bass Strait. The region sustains a diverse range of land uses, including grazing, dairy, cropping, plantation and native forestry, mining, heavy industry, urban, rural residential and nature conservation areas. It provides substantial input to Tasmania's economy as well as sustaining key ecological assets and communities. There are 26 wastewater treatment plants discharging into the rivers and estuary, many of which are near the end of their lifecyle and in need of upgrade. There are also a number of aquaculture operations including salmonid hatcheries at Upper Esk, Targa and Cressy, a salmonid sea farm at Rowella, seahorse farm at Beauty Point and an abalone farm at Clarence Point.

Partnership approaches, such as the Chesapeake Bay Program in the USA and Healthy Waterways in Queensland, have been shown to be successful at improving environmental outcomes. These programs seek to facilitate communication and collaboration between government, research organisations and industry to overcome barriers to knowledge sharing and improved management. They are particularly useful in catchments where there are a complex array of stakeholders and issues (see for example Imperial, 2005; Leach and Pelkey, 2001). To provide a coordinated management approach and guide for investment in activities to protect, maintain and restore the health of the catchment, NRM North established the Tamar Estuary and Esk Rivers

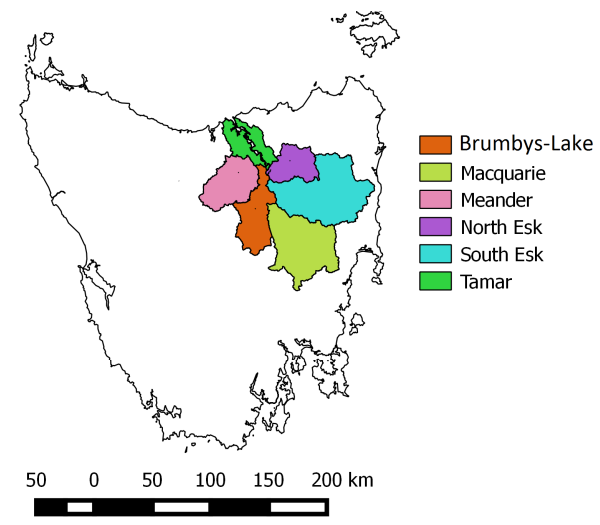

Figure 1. TEER catchment and its subcatchments

Program (TEER) in 2008. A key goal of the TEER Program is to improve scientific understanding of the issues impacting upon the health of waterways so that priority areas requiring investment in on-ground works can be better identified and targeted.

The TEER Program is a regional partnership between the agencies with a statutory responsibility for waterway management and includes local and state governments, Hydro Tasmania and TasWater. The TEER Program also fosters collaborative partnerships and works closely with a range of industry, business, research, government and community groups to coordinate activities to reduce pollutants entering waterways and to monitor and report on waterway health. In 2013, the TEER program embarked on the development of a Water Quality Improvement Plan (WQIP) to integrate the scientific investigations previously undertaken for the catchment and estuary, and develop a long term vision for the catchment and estuary in collaboration with the community.

WQIPs are a planning process developed by the Australian Federal Government through its Coastal Catchments Initiative. A WQIP provides an ecosystem based approach to integrated water cycle management, supported by science. Water Quality Improvement Plans were originally developed for 12 major estuary systems Australia wide, including the Great Lakes in NSW, Derwent estuary, Botany Bay, Moreton Bay and the Swan Canning Estuary (see for example Pfennig, 2008; Swan River Trust, 2009; Great Lakes Council, 2009; EPA, 2008; Derwent Estuary Program, 2007; SMCMA, 2011). WQIP are designed to:

- $\quad$ engage state, local government, NRM groups and cooperatively prepare a WQIP and implement interim projects

- resolve major impediments to Water Quality planning and management through a catchment management based approach

- address the key priority threats to water quality and environmental flows, and establish methods to continuously improve management knowledge and systems

- $\quad$ establish governance arrangements that ensure all relevant stakeholders are party to WQIP implementation (adapted from Dept. of Environment, 2011).

A Water Quality Improvement Plan (WQIP) has been developed for the Tamar Estuary and Esk Rivers (TEER) catchment area to:

- $\quad$ Provide a comprehensive whole-of-catchment picture of water quality in the Tamar estuary and its tributaries.

- Develop an understanding of the drivers of any water quality issues and the levers that can be used to address these.

- Identify priority activities to address water quality issues. 
It is recognised that the Plan will need to be implemented by a range of key stakeholders so catchment stakeholders have been engaged throughout its development. This Plan aims to provide direction to all catchment stakeholders on the role they can play in protecting and improving water quality in the TEER catchments. This paper describes the development of the Plan and gives an example of some of the analysis used to develop the Plan's recommendations.

\section{PLAN DEVELOPMENT PROCESS}

This WQIP has been developed over three main phases: Initial scoping; Decision Support System (DSS) and scenario development and; WQIP and recommendations. Each phase of the plan process involved consultation and engagement with the community and/or key stakeholders, where those engaged could provide suggestions and feedback on the direction and content of the WQIP.

\subsection{Scoping Phase}

The main direction and development of the TEER WQIP was determined as part of the initial scoping phase. This involved the establishment of a WQIP Working Group, key stakeholder workshops, community forums and an online survey.

In October 2013, three community forums and an online survey were conducted to inform the community of the development of a WQIP. Community forums were held with the aim to educate the community about the WQIP objectives and to seek community input on scenarios, impacts and management actions to be considered in the Plan. Facilitated discussions at the workshops were based on three main themes:

- Values: What do you most value about the catchment, rivers and estuary? What do you use them for? What attributes would you like to see protected?

- Impacts: What are you most concerned about in terms of the future health of the river and estuary? What changes do you see could harm the estuary and rivers? What changes do you see that could benefit the estuary or rivers?

- Management actions: What opportunities do you see to improve and protect our rivers and estuary? What actions do you think should be taken to protect and enhance water quality in the rivers and estuary?

Four key stakeholder workshops involving participants with interests in Forestry, Primary industry and land conservation, health and ecology of the Tamar and the Northern Tasmanian Stormwater Working Group were also held in October 2013. These workshops were designed to seek comment on possible management actions and scenarios to be considered in the Plan and how these would be handled in the DSS and to determine subcatchments and estuary zones to be used in the DSS and the Plan. One-on-one consultations were also held with key stakeholders as required.

\subsection{Decision Support System and Scenario Development}

The scoping workshops and community forums identified a range of actions and potential sources of pollutants to the TEER waterways. This feedback was used to develop the TEER CAPER DSS (see Kelly, 2015). This DSS has been developed to allow the impact of land use and management change scenarios on catchment loads and estuary water quality to be assessed. Sources of pollutants and potential management actions identified by key stakeholders were used to develop the conceptual framework underlying the integrated model that underpins the DSS. As shown in Figure 2 the conceptual framework includes management modules for WWTP, stormwater, grazing, forestry, dairy, willows, cropping \& horticulture and aquaculture. These link to a catchment export model, in this case a metamodel of the Source Catchments model and an estuary water quality model, a metamodel of a 2D hydrodynamic model.

Management modules use: metamodels of detailed calibrated models previously developed for the catchment, such as the MUSIC model for considering water sensitive urban design; empirical models based on monitoring data (eg. for WWTPs); and, literature based models. Management modules underwent review by four independent peer reviewers to ensure they captured the best available science and understanding of processes. 
A preliminary set of spatial scales was also developed for subcatchments to align with key planning reports and literature available in Tasmania. These were further refined using comments from key stakeholders before being used in the DSS.

Following this, the interface of the DSS was developed and text documents collated. The role of the DSS is to assess the impacts of various management actions, future land use and population scenarios on catchment and estuary water quality. Scenarios suggested by key stakeholders were evaluated in the DSS. Workshops were run in September 2014 to provide DSS training to key stakeholders, seek feedback on preliminary results and to determine the scenarios to be included in the Plan, including feasible

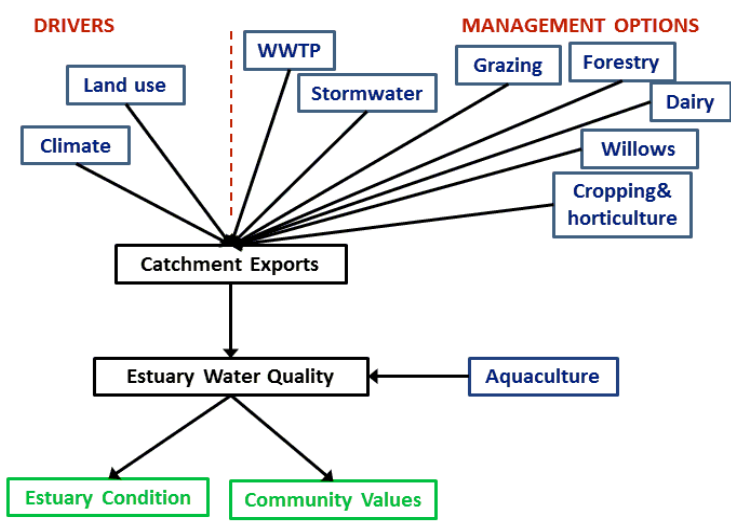

Figure 2. Conceptual model underlying the TEER CAPER DSS adoption rates for various management scenarios.

\subsection{WQIP and recommendations}

Scenarios selected by key stakeholders for inclusion in the WQIP were analysed in the DSS and included in drafts of the Plan along with preliminary recommendations before being circulated to key stakeholders for comment. Presentations of relevant scenarios and preliminary recommendations were given separately to key stakeholders such as Local Councils and industry groups. The selected scenarios have been used to illustrate the effects of management actions and pressures on water quality and to develop WQIP recommendations in consultation with key stakeholders. Negotiations of recommendations in light of scenario impacts has been undertaken with stakeholders before these have been included in the WQIP.

\section{SCENARIOS IN THE WQIP}

Numerous scenarios were developed and modelled using the CAPER DSS as part of the WQIP. Assumptions underpinning these scenarios were based on feedback from stakeholder workshops held throughout the Plan development. Scenarios had various purposes:

- To explore the contributions of different point and diffuse sources to current and potential future pollutant loads.

- To demonstrate the benefits of past management actions, such as the Forest Practices Code.

- To explore the impacts of potential future land use change such as urban development and dairy expansion, with and without best management practices.

- To assess the leverage and effectiveness of potential management actions on current land uses to prioritise management actions. These scenarios assumed different levels of adoption for different incentive and education programs, based on key stakeholder feedback on rates of adoption.

A set of load targets was also developed using the CAPER DSS based on feasible levels of adoption of BMP across all land uses, using both current land use configuration and population as well as potential future land use and population.

\section{EXAMPLE: POTENTIAL LAND USE CHANGE - DAIRY EXPANSION}

This section provides an overview of one of the scenarios, potential expansion of the dairy industry, considered in the TEER WQIP. The WQIP contains numerous scenarios that have been modelled using the CAPER DSS relating to management practice and potential land use change, highlighting the role that each of us can play in protecting and improving water quality. 
The contribution of different land uses to diffuse pollutant loads of total nitrogen (TN), total phosphorus (TP), total suspended sediments (TSS) and enterococci from the Greater TEER catchment is shown in Figure 3. This figure shows that dairy areas are currently not a significant source of nutrients or sediments at the Greater TEER catchment scale, although they are a significant source of pathogens and are a major source of water quality issues in some subcatchments.

Over the coming years substantial increases in dairy areas and dairy cow numbers are expected to be seen in the TEER catchment. While dairy currently contributes relatively small proportions of the total loads generated in the catchment, this expansion has the potential to lead to significant declines in water quality if expansion occurs without adequate adoption of best management practice (BMP).

Analysis has been undertaken using the TEER CAPER DSS to explore the impacts of potential options for expansion with varying levels of adoption of BMP. Four different dairy expansion options have been analysed to test whether they have a significant impact on the

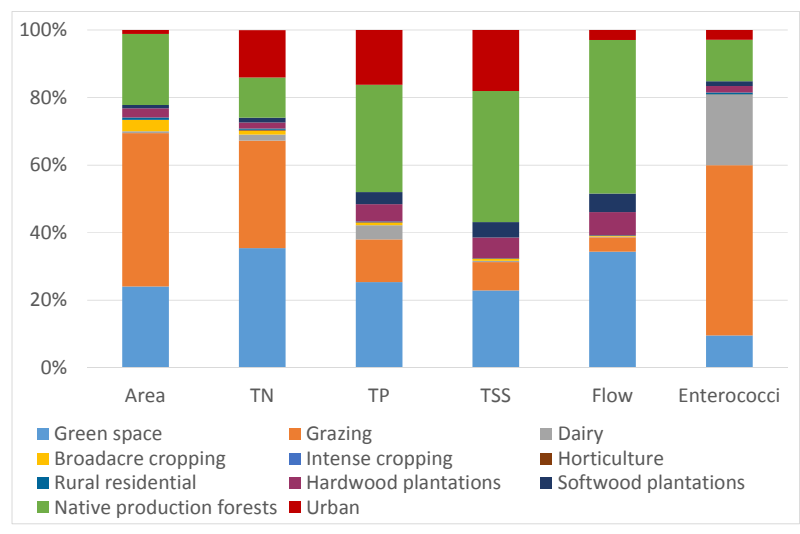

Figure 3. Sources of diffuse pollutant loads in the TEER catchment impacts of dairy expansion: broadscale expansion on grazing or cropping areas; intensive expansion on grazing or cropping areas. All options considered the scenario where an additional 38,000 dairy cows are incorporated in the TEER catchment. Assumptions for where expansion would occur and its impacts on areas and stocking rates in these subcatchments have been provided by Dairy Tasmania.

These potential futures were then considered with 3 levels of management practices:

- 'No BMP' - New areas have no BMP implemented (no change in practice on existing areas);

- 'Current BMP' - New areas have BMP applied to the same extent as current areas; and,

- 'All BMP' - New areas have 100\% BMP applied (no change in practice on existing areas).

Management practices tested on dairy areas are:

- Sufficient effluent storage is available;

- Stock are excluded from streams with off-stream water provided;

- $\quad 20 \mathrm{~m}$ wide riparian buffers are created along all streams;

- Drains are vegetated to capture pollutants;

- Irrigation is managed to minimise pollutant loss;

- Fertiliser use is managed using nutrient budgets, with timing and application rates designed to minimise pollutant runoff; and,

- Laneways are managed to reduce manure accumulation and runoff.

Figure 4 shows results for broadscale expansion on grazing areas only. While impacts differ between the different expansion scenarios, the general story remains relatively unchanged regardless of where expansion occurs or its intensity.

This figure shows:

- Without best management practices, dairy expansion could lead to substantial increases in nutrients, sediments and pathogens. The Brumbys-Lake lowlands and South Esk lowlands generally experience the greatest increases in loads for all pollutants. Very large increases in pathogens can be expected with enterococci expected to increase by 3 to over 7 times current levels under the 'No BMP' option.

- Expanding dairy using current levels of BMP adoption can still be expected to lead to declining water quality, although the increases in pollutant loads would be much less than under the 'No BMP' option (roughly to $20-40 \%$ of the 'No BMP' increase).

- Expanding dairy using 100\% BMP adoption reduces impacts on water quality. In this case pollutant loads are constrained so that there is little to no increase. In some cases a small improvement in water quality can be expected.

Impacts in each catchment depend on the land use being converted and its current management practice. In general, dairy areas have good groundcover and contribute little sediment load. Their contribution to nutrient loads per hectare of land use is generally higher, and higher stocking rates means that, where stock have access 
to streams, dairy expansion can lead to substantial increases in enterococci. Feedback from stakeholders suggests that dairy farmers are more likely to amenable to excluding stock from streams than many dryland graziers.

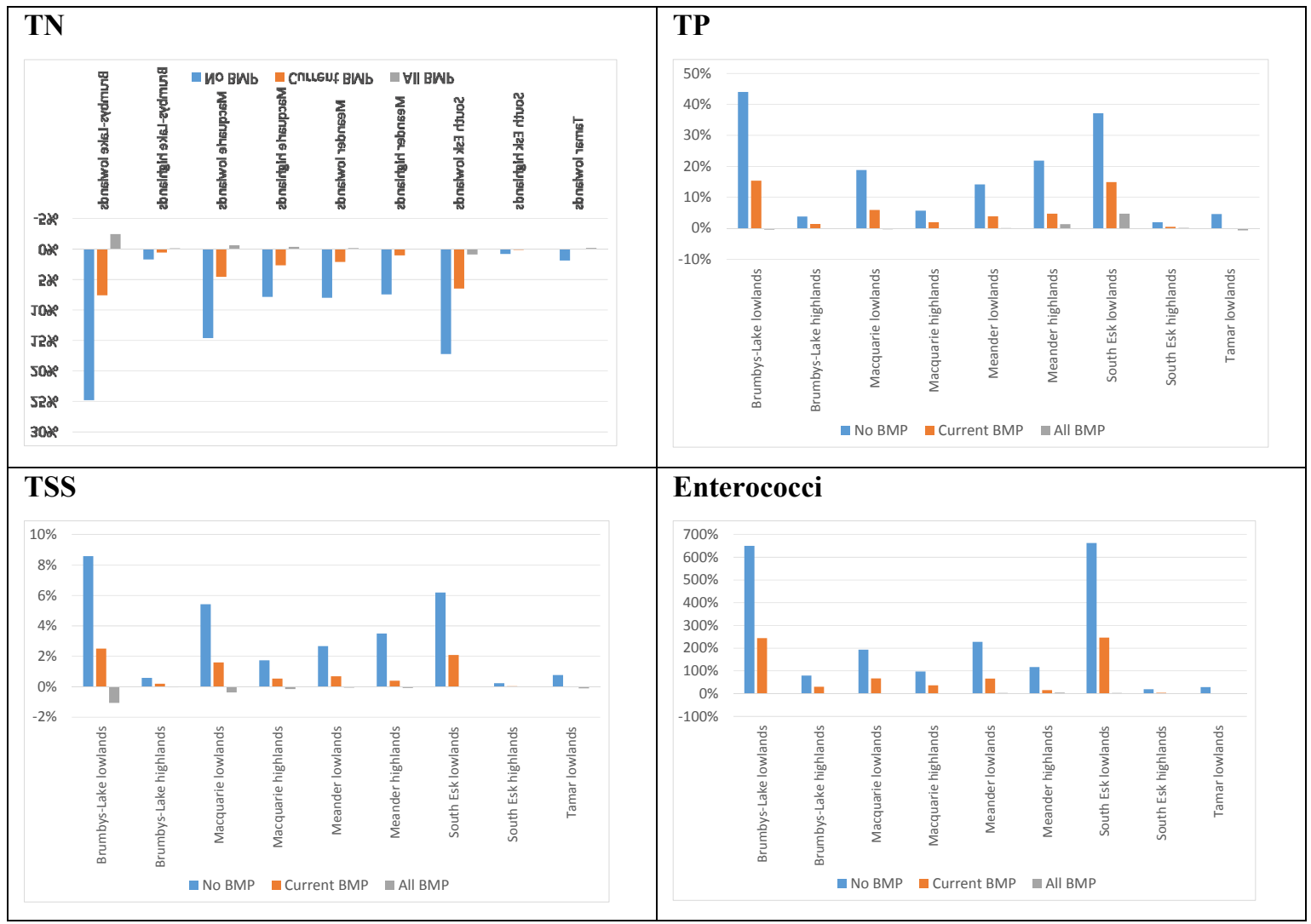

Figure 4. Impacts of dairy expansion scenarios on pollutant loads

The individual influence of each potential management action on pollutant loads was explored using the CAPER DSS. It was found that enterococci loads are driven almost entirely from stock access to streams, with manure deposited directly near the stream having the greatest impact on pathogen loads. Small changes in sediment loads can be achieved by restricting stock access to streams and ensuring dairy farms have sufficient effluent storage. Similarly nutrient loads can be reduced by limiting stock access and provision of sufficient effluent storage. Drain and irrigation management also have some impact on nutrient loads, although this is much smaller than for the other actions.

These results show that dairy expansion can be viewed as both a threat and an opportunity in terms of water quality. Without high levels of adoption of BMP, dairy expansion can be expected to lead to significant increases in nutrient, sediment and particularly pathogen loads to the system. However if expansion occurs with high levels of BMP adoption, these impacts can be reduced substantially, to the point where, in some cases, dairy expansion could lead to improvements in water quality where it replaces other land uses that are currently poorly managed or otherwise associated with high levels of pollutant export. Note that adoption of BMP on current dairy areas provides a further opportunity to improve water quality and to provide a buffer against potential future increases in loads from land use or other changes.

Management priorities in dairy areas, both existing and future expansion areas are:

- Sufficient effluent storage should be provided for on dairy farms. This storage should be well-designed and placed to ensure effluent can be applied to an adequate area of the farm, and such that storages are unlikely to leach or overflow effluent.

- Stock should be restricted from all streams on dairy farms wherever it is feasible. The inclusion of riparian buffers is likely to have very small benefits for water quality given the extensive use of drains, however could be expected to benefit stream health through shading, increased bank stability, increased connectivity between vegetation remnants and provision of wildlife corridors. Creation of riparian buffers should be encouraged for these reasons, however for water quality the most important outcome 
in most cases is that stock are removed from streams. Thus management should be flexible to allowing for this with either minimal or no buffers where this is likely to achieve greater adoption of this action.

- Irrigation scheduling should be managed to match irrigation to soil infiltration rates and pasture growth rates, and irrigation water reused to reduce drainage losses where possible.

- Drains need to be managed to minimise the transport of pollutants off-farm. This presents some practical challenges for dairy farmers and more consultation is needed to develop practical solutions for BMP.

\section{RECOMMENDATIONS AND PLAN IMPLEMENTATION}

The TEER WQIP provides a comprehensive assessment of the current condition of the TEER catchments, the source of pollutants to the estuary and potential impacts of future land use changes. This paper has given an overview of one of the scenarios presented in the WQIP, the potential impacts of dairy expansion on water quality. Other scenarios included in the Plan are:

- Sources of diffuse and point source pollution.

- Management actions to improve water quality from grazing areas and cropping areas.

- The impacts of the Forest Practices Code on water quality.

- Impacts of urban development proposed in the Greater Launceston Plan with and without water sensitive urban design.

- The potential for water sensitive urban design and erosion and sediment control to impact water quality from existing urban areas.

- Impacts of the current proposed option for the Launceston Sewage Improvement Plan.

- The contribution of salmon farming to water quality in the estuary.

A set of load targets given current population and land use and potential future population and land use using feasible levels of adoption across these actions is also provided based on analysis of results from the TEER CAPER DSS.

Results shown in this paper and for other scenarios in the Plan reinforce that while change is often seen as a threat to the environment, it is also an opportunity for improvement if it can be undertaken with high levels of adoption of BMP. Scenarios explored in the WQIP show that it is possible that sustainable development can at least arrest any decline in water quality, and at best can improve water quality.

\section{ACKNOWLEDGMENTS}

The TEER WQIP has been funded through partner contributions to the TEER program, facilitated through NRM North. Dairy Tasmania provided assumptions for expansion scenarios, reviewed model components, scenario analysis and recommendations. Thanks also goes to all the stakeholders who engaged in development of the Plan.

\section{REFERENCES}

Dept. of Environment (2011). Water Quality Improvement Plans, http://www.environment.gov.au/water/quality/improvement, accessed June 2011.

Derwent Estuary Program (2007). Derwent Estuary Water Quality Improvement Plan for Heavy Metals, prepared by the Derwent Estuary Program with support from the Australian Government Coastal Catchments Initiative, Tasmanian State Government and Derwent Estuary Program partnership, June 2007.

Environmental Protection Authority (2008). Water Quality Improvement Plan for the Rivers and Estuary of the PeelHarvey System - Phosphorus Management, Environmental Protection Authority, Perth, Western Australia.

Great Lakes Council (2009). Great Lakes Water Quality Improvement Plan: Wallis, Smiths and Myall Lakes, Forster NSW.

Imperial, M.T. (2005). Using collaboration as a governance strategy: lessons from sic watershed management programs. Administration \& Society, 37(3), 281-320.

Kelly, R.A. (2015). Using Decision Support for Water Quality Improvement Planning: the CAPER DSS, MODSIM 2015.

Kelly, R.A, A. Locatelli, and M. White (2015). Water Quality Improvement Plan for the Tamar Estuary and Esk rivers, NRM North, Launceston.

Leach, W.D. and Pelkey, N.W. (2001).Making watershed partnerships work: a review of empirical literature. Journal of Water Resources Planning and Management, 127(6), 378-85.

Pfennig, P. (2008). Port Waterways Water Quality Improvement Plan, Environmental Protection Authority, South Australia, May 2008.

Swan River Trust (2009). Swan Canning Water Quality Improvement Plan, Perth, Western Australia.

Sydney Metropolitan Catchment Management Authority (2011). Botany Bay \& Catchment Water Quality Improvement Plan Sydney: Botany Bay Water Quality Improvement Program. 